\title{
Synthesis of Cruentaren A
}

\author{
Bhaskar Reddy Kusuma ${ }^{\dagger}$, Gary E. L. Brandt ${ }^{\dagger}$, and Brian S. J. Blagg \\ Department of Medicinal Chemistry, The University of Kansas, 1251 Wescoe Hall Dr, Malott \\ 4070, Lawrence, Kansas 66045-7562
}

Brian S. J. Blagg: bblagg@ku.edu

\section{Abstract}

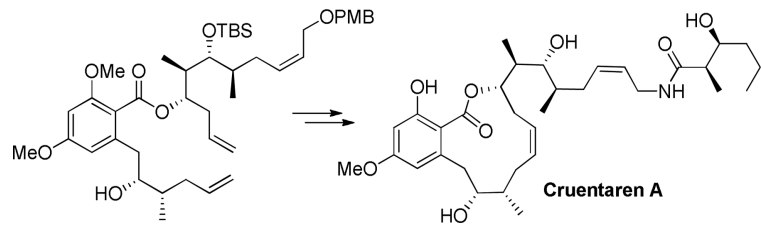

Cruentaren A, an antifungal benzolactone produced by the myxobacterium Byssovorax cruenta, is highly cytotoxic against various human cancer cell lines and a highly selective inhibitor of mitochondrial F-ATPase. A convergent and efficient synthesis of cruentaren A is reported, based upon a diastereoselective alkylation, a series of stereoselective aldol reactions utilizing Myers' pseudoephedrine propionamide, an acyl bromide-mediated esterification and a ring-closing metathesis (RCM) as the key steps. The RCM reaction was applied for the first time towards the total synthesis of cruentaren A, which led to a convergent and efficient synthesis of the natural product.

Cruentaren A and its isomeric analogue, cruentaren B, have been identified as the first novel structures isolated from the fermentation broths of Byssovorax cruenta by Hofle et al. ${ }^{1,2}$ Cruentaren A (1) was the major natural product, which was isolated through bioassay guided fractionation that focused upon the identification of novel antifungal and cytotoxic agents. While cruentaren A demonstrated potent cytotoxic effects ( IC $_{50}$ of $8.3 \mathrm{nM}$ against $\mathrm{L} 929$ mouse fibroblasts), its closely related derivative, cruentaren $\mathrm{B}$, was only marginally active. ${ }^{3}$

Cruentaren A is a member of the growing class of benzolactone natural products that contains a resorcinol derived 12-membered macrocyclic lactone and an $\mathrm{N}$-acylallylamine side chain (Figure 1). ${ }^{4}$ Despite structural similarities to other natural products of this class, cruentaren A possesses a unique mechanism of action. This natural product induces cytoxicity through selective inhibition of F-ATPase, but is devoid of inhibitory activity against other ATPases. ${ }^{1-3}$

Due to the interesting architecture and a unique biological profile, cruentaren A has attracted significant attention from the synthetic community. Four successful total syntheses and numerous approaches to fragments have been reported. ${ }^{5,6,7,8}$ In fact, all published syntheses rely upon the ring-closing alkyne metathesis (RCAM) reaction as a key step, followed by Lindlar reduction to introduce the cis-olefin that is present within the macrocyclic ring. Due

Correspondence to: Brian S. J. Blagg, bblagg@ku . edu.

${ }^{\dagger}$ Both authors contributed equally to this work.

Supporting Information Available. Experimental procedures and full spectroscopic data for all new compounds. This material is available free of charge via the internet at http://pubs.acs.org. 
to the publication of prior existing routes, we pursued an alternate method that does not rely upon the RCAM in an effort to ultimately produce analogs that are not easily obtained through other routes. Herein, we report the total synthesis of cruentaren A that utilizes the RCM reaction for construction of the desired cis-macrocyclic product.

Retrosynthetic analysis of cruentaren A (1), utilizing the RCM reaction for construction of the 12-membered lactone, required fragments $\mathbf{2}$ and $\mathbf{3}$ as relevant synthons. Weinreb amide $\mathbf{5}$ could then be reacted with the benzylic anion of 6 to provide ketone intermediate 4 , which would enable subsequent metathesis to form 2 . Likewise, esterification of secondary alcohol $\mathbf{7}$ would provide substrate $\mathbf{6}$ and after RCM, the macrocycle. Staudinger ligation between the allylazide of $\mathbf{2}$ and acid $\mathbf{3}$ was envisioned to occur before global deprotection to provide the natural product. Successful stereochemical induction with Myers' pseudoephedrine chiral auxiliary would be required throughout this synthetic strategy. Specifically, the synthesis of allyl alcohol 7 was envisioned to depend upon Myers' psueodoephedrine to construct all three stereocenters through sequential reactions (Figure 2). Myers' psueodoephedrines are readily available from inexpensive, commercially available reagents via a simple one step process and furthermore, these chiral auxiliaries can be elaborated into a variety of useful entities through well-described synthetic protocols. ${ }^{9}$

In the event, alkylation of $(S, S)$-pseudoephedrine propionamide 9 with cis-allyl bromide $\mathbf{8}^{10}$ proceeded smoothly under Myers' optimized conditions ${ }^{11}$ to provide the diastereomerically enriched methyl amide $\mathbf{1 0}(>20: 1)$, which upon subsequent lithium aluminium hydride reduction gave the corresponding aldehyde, 11. Induction of stereochemistry at C-16 and $\mathrm{C}-17$ was accomplished through use of a zirconium-mediated aldol reaction ${ }^{9}$ between the (Z)-enolate of propionamide $\mathbf{1 2}$ and aldehyde $\mathbf{1 1}$ to give diastereomerically pure $\mathbf{1 3}$ (Scheme 1).

Carboxylic acid $\mathbf{1 4}$ was accessed by mild hydrolysis of $\mathbf{1 3}$ followed by conversion to the Weinreb amide 15 using the (1-Cyano-2-ethoxy-2-oxoethylidenaminooxy)dimethylaminomorpholino-carbenium hexafluorophosphate (COMU) coupling reagent. COMU is a $3^{\text {rd }}$ generation uronium-type coupling reagent that is commonly used for solution-phase peptide synthesis; the by-products produced with COMU are water soluble and easily removed. Furthermore, COMU exhibits a less hazardous safety profile than benzotriazole-based reagents and prevents recemization during the coupling event. ${ }^{12}$ The secondary alcohol of 15 was protected as the tert-butyldimethylsilyl ether before subsequent reduction of the amide to give aldehyde 17. Upon treatment of $\mathbf{1 7}$ with in situ generated Soderquist's allylborane intermediate that was generated upon exposure of allyl Grignard to $18,{ }^{13} \mathrm{a}$ highly enantio-enriched homoallylic alcohol 7 was produced with excellent facial selectivity.

Stereochemical assignment of advanced intermediate $\mathbf{7}$ was accomplished by Mosher's ester analysis, ${ }^{14}$ which validated the desired syn stereochemistry of the 1,3-diol relationship for 7. To determine the relative stereochemical relationship of the $\mathrm{C}-16$ methyl group, acidmediated TBS hydrolysis and subsequent acetonide protection of the resultant 1,3-diol enabled formation of $\mathbf{1 9}$, which was shown to exhibit the correct stereochemical relationship as deterimined by Rynchnovsky's method (Scheme 2). ${ }^{15}$

The synthetic route to provide Weinreb amide fragment 5 was straightforward and provided a rapid means to generate significant quantities of this intermediate for the optimization of latter steps. Alkylation of propionamide $\mathbf{1 2}$ with allyl bromide under Myers' conditions generated a-methyl amide, 20 ( $\mathrm{dr}>20: 1)$. Hydrolysis and subsequent COMU-mediated coupling produced Weinreb amide $\mathbf{5}$ without loss of enantioenrichment on multi gram scale. A similar zirconium-mediated aldol reaction between propionamide $\mathbf{9}$ and butanal as 
described above to provide amide $\mathbf{2 2}$ followed by hydrolysis, gave carboxylic acid $\mathbf{3}$ without diastereomeric loss. The successful COMU-mediated coupling reaction ${ }^{16}$ suggested that the hydroxyl group of compound $\mathbf{3}$ did not require protection. Therefore, the free alcohol of $\mathbf{3}$ was left unprotected (Scheme 3).

Construction of the macrocyclic ring involved esterification of allylic alcohol 7 with commercially available benzoic acid 22. Synthesis of ester $\mathbf{6}$ proved to be challenging and unsuccessful results were obtained following the methods reported by Furstner and Vintonyak for the related alkynyl derivative. ${ }^{4,5}$ After a significant investment of time and effort, synthesis of ester $\mathbf{6}$ was finally achieved upon treatment of acid $\mathbf{2}$ with oxalyl bromide $(\mathrm{COBr})_{2}$, DIPEA, and catalytic DMF in DCM at $0{ }^{\circ} \mathrm{C}$ for $30 \mathrm{~min}$, followed by the addition of alcohol 3 and 4-(dimethylamino)pyridine (DMAP). Complete conversion to desired ester $\mathbf{6}$ occurred within $10 \mathrm{~min}$ in high yield. Alkylation of $\mathbf{6}$ with Weinreb amide 5 proceeded by generation of the benzylic anion of 6 to produce advanced intermediate 4 in reasonable yield (Scheme 4).

Prior to RCM of the terminal olefins, stereoselective reduction of ketone $\mathbf{4}$ was considered. Attempts to affect stereoselective reduction of ketone $\mathbf{4}$ under various conditions enlisting the CBS reagent were unsuccessful as $\mathbf{4}$ was highly resistant to reduction under these constraints. However, reduction of ketone $\mathbf{4}$ utlizing Noyori's asymmetric transfer hydrogenation conditions proved successful. ${ }^{17,18}$ In the event, ketone $\mathbf{4}$ was treated with sodium formate and catalytic $\mathrm{RuCl}[(\mathrm{S}, \mathrm{S})$-Tsdpen](p-cymene) in DMF and water to generate alcohol 23 in quantitative yield and reasonable diastereomeric selectivity ( 5:1). Unfortunately, the epimeric product was not separable via column chromatography at this stage (Scheme 4).

Consequently, a mixture of diastereomeric alcohols (23) was subjected to RCM catalysis, and gratifyingly, the cis-olefin containing macrocycle was obtained in diastereomerically pure form, and the alcohol epimers were readily separable via column chromatography. Unfortunately, an unexpected side reaction did occur, in which cis to trans isomerization of the allylic ether side chain was observed. Several solvents, including THF, benzene, and methanol were screened, however, the most minimal isomerization occured in DCM. The optimized reaction conditions included the addition of $5 \mathrm{~mol} \%$ of catalyst at $0{ }^{\circ} \mathrm{C}$ to a 0.5 $\mathrm{mM}$ solution of alcohol $\mathbf{2 3}$ in DCM, followed by warming to $20^{\circ} \mathrm{C}$. RCM was complete after $3.5 \mathrm{~h}$, but required treatment with saturated aqueous potassium carbonate $\left(\mathrm{K}_{2} \mathrm{CO}_{3}\right)$ for catalyst deactivation in order to prevent additional isomerization during work-up. These reaction conditions furnished the epimerically pure cis-macrocyclic product, $\mathbf{2 4}$, in $\mathbf{7 9 \%}$ yield as a 4:1 (cis:trans) mixture of the olefinic side chain isomers. Compound $\mathbf{2 4}$ was then sequentially TBS-protected at C-8 to generate 25 , followed by PMB-removal to give allyl alcohol 26.

Conversion of $\mathbf{2 6}$ to cruentaren A, and completion of the total synthesis involved four additional manipulations (Scheme 5). The allylic alcohol of $\mathbf{2 6}$ was converted to the corresponding allyl-azide (2) upon treatment with $\mathrm{Zn}\left(\mathrm{N}_{3}\right)_{2}$ (pyridine) $)_{2},{ }^{19}$ diisopropyl azodicarboxylate and triphenylphosphine. One-pot azide reduction and COMU-mediated amide formation was achieved via Staudinger ligation conditions to provide the protected variant of cruentaren A (27) as a single diastereomer. Cleavage of the C-3 methyl ether was achieved by subjecting compound $\mathbf{2 7}$ to boron trichloride in DCM at low temperature, followed by removal of the corresponding bis(TBS-ether) with HF-pyridine in acetonitrile to furnish cruentaren A (1). The spectroscopic data for synthetic cruentaren A (1) were in agreement with data reported for the natural product. ${ }^{1}$ 
In summary, a convergent and efficient total synthesis of cruentaren A has been described with a longest linear sequence of 18 steps. The synthesis is dependent upon the use of Myers' diastereoselective alkylation, a series of stereoselective aldol reactions utilizing pseudoephedrine propionamide, a Soderquist allyaltion, an acyl bromide-mediated esterification, and RCM as the key steps. Additional studies for cruentaren A and analogues are currently under investigation with the goal of more thoroughly understanding the role FATPase plays in the maturation of nascent polypeptides..$^{20,21,22}$ The results from such studies will be disclosed in due course.

\section{Supplementary Material}

Refer to Web version on PubMed Central for supplementary material.

\section{Acknowledgments}

The authors gratefully acknowledge the support of this project by NIH (CA109265). G.E.L.B. acknowledges the Madison and Lila Self Graduate Fellowship and the American Foundation for Pharmaceutical Education for financial support.

\section{References}

1. Jundt L, Steinmetz H, Luger P, Weber M, Kunze B, Reichenbach H, Hofle G. Euro. J. Org. Chem. 2006; 22:5036-5044.

2. Kunze B, Steinmetz H, Hofle G, Huss M, Wieczorek H, Reichenbach H. J. Antibiot. 2006; 59:664668. [PubMed: 17191683]

3. Kunze B, Sasse F, Wieczorek H, Huss M. FEBS Lett. 2007; 581:3523-3527. [PubMed: 17624334]

4. Boyd MR, Farina C, Belfiore P, Gagliardi S, Kim JW, Hayakawa Y, Beutler JA, McKee TC, Bowman BJ, Bowman EJ. J. Pharmacol Exp Ther. 2001; 297:114-120. [PubMed: 11259534]

5. (a) Bindl M, Jean L, Hermann J, Muller R, Furstner A. Chem. Eur. J. 2009; 15:12310-12319. [PubMed: 19821471] (b) Furstner A, Bindl M, Jean L. Angew. Chem. Int. Ed. 2007; 46:9275-9278.

6. (a) Vintonyak VV, Cala M, Lay F, Kunze B, Sasse F, Maier ME. Chem. Eur. J. 2008; 14:3709_ 3720. [PubMed: 18306263] (b) Vintonyak VV, Maier ME. Org. Lett. 2007; 9:655-658. [PubMed: 17256947] c) Vintonyak VV, Maier ME. Angew. Chem. Int. Ed. 2007; 46:5209-5211.

7. Fouche M, Rooney L, Barrett AGM. J. Org. Chem. 2012; 77:3060-3070. [PubMed: 22401367]

8. Ramalinga B, Prasad V, Meshram HM. Tetrahedron: Asymmetry. 2010; 21:1837-1844.

9. Maier ME, Ritschel J. ARKIVOC. 2008; xiv:314-329.

10. Sreedhar E, Venkanna A, Chandramouli N, Babu KS, Rao JM. Eur. J. of Org. Chem. 2011; 6:1078-1083.

11. (a) Myers AG, Yang BH, Chen H, McKinstry L, Kopecky DJ, Gleason JL. J. Am. Chem. Soc. 1997; 119:6496-6511.(b) Rodriguez M, Vicario JL, Badia D, Carrillo L. Org. Biomol. Chem. 2005; 3:2026-2030. [PubMed: 15889187]

12. (a) El-Faham A, Funosas RS, Prohens R, Albericio F. Chem. Eur. J. 2009; 15:9404-9416. [PubMed: 19621394] (b) Fahama EL, Albericioa F. J. Pept. Sci. 2010; 16:6-9. [PubMed: 19950108]

13. Canales EK, Prasad G, Soderquist JA. J. Am. Chem. Soc. 2005; 127:11572-11573. [PubMed: 16104712]

14. (a) Rieser MJ, Hui YH, Rupprecht JK, Kozlowski JF, Wood KV, McLaughlin JL, Hanson PR, Zhuang Z, Hoye TR. J. Am. Chem. Soc. 1992; 114:10203-10213.(b) Hoye TR, Jeffrey CS, Shao F. Nat. Protoc. 2007; 2:2451-2458. [PubMed: 17947986]

15. Rychnovsky SD, Richardson TI. J. Org. Chem. 1997; 62:2925-2934. [PubMed: 11671656]

16. Samarasimhareddy M, Hemantha Hosahalli P, Ananda K, Sureshbabu VV. Prot. Pept. Lett. 2012; 19:406-410.

17. Gladiali S, Alberico E. Chem. Soc. Rev. 2006; 36:226-236. [PubMed: 17264925] 
18. Noyori R, Hashiguchi S. Acc. Chem. Res. 1997; 30:97-102.

19. Viaud MC, Rollin P. Synthesis. 1990:130-132.

20. Papathanassiu AE, MacDonald NJ, Bencsura A, Vu HAF. Biochem. Biophys. Res. Commun. 2006; 345:419-429. [PubMed: 16682002]

21. Papathanassiu AE, MacDonald NJ, Emlet DR, Vu HA. Cell Stress Chaperones. 2011; 16:181-193. [PubMed: 20927616]

22. Francis BR, Thorsness PE. Mitochondrion. 2011; 11:587-600. [PubMed: 21439406]

Org Lett. Author manuscript; available in PMC 2013 December 21. 


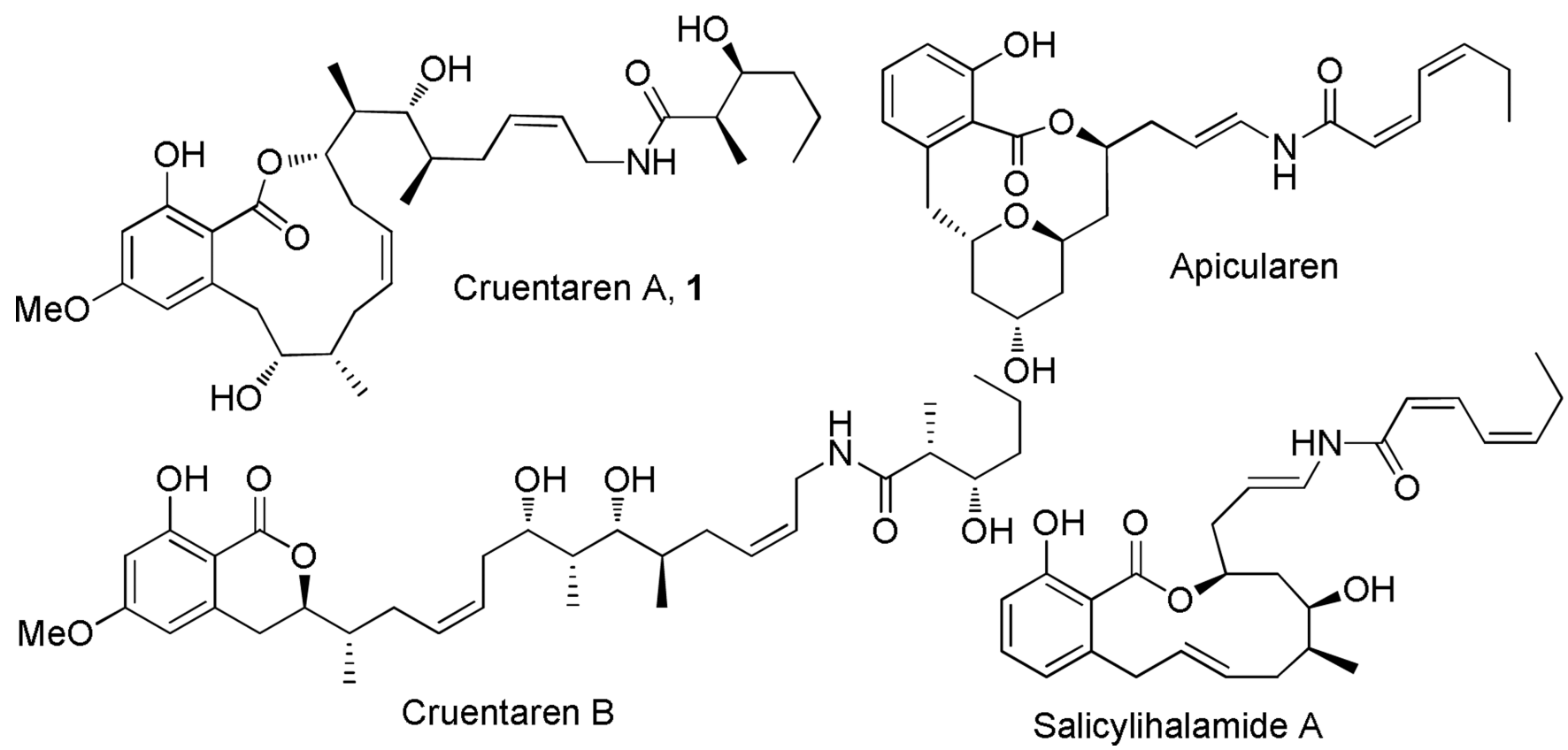

Figure 1.

Benzolactone natural product family. 
<smiles>[B-]O[C@@H]([C@@H](C)C/C=C\CO[R16](C)(C)C)[C@H](C)[C@@H](CC=C)OC(=O)c1c(CC(=O)[C@@H](C)CC=C)cc(OC)cc1OC</smiles>

Figure 2.

Retrosynthtic analysis of cruentaren A (1). 


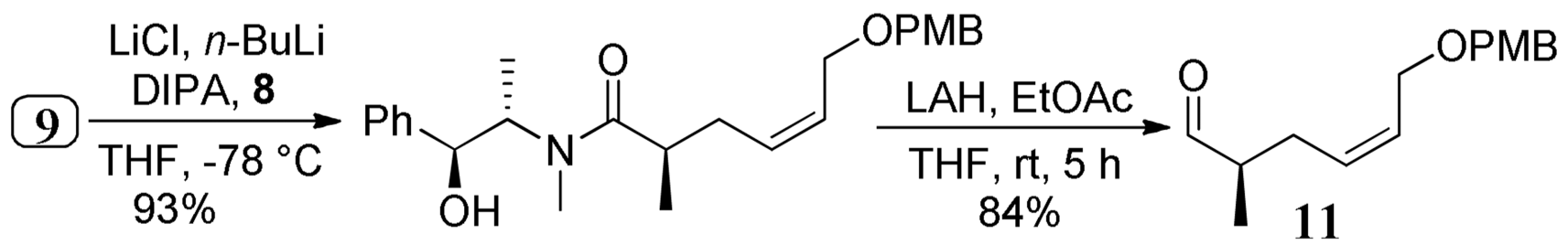

$$
\begin{aligned}
& 10(d r>20: 1)
\end{aligned}
$$

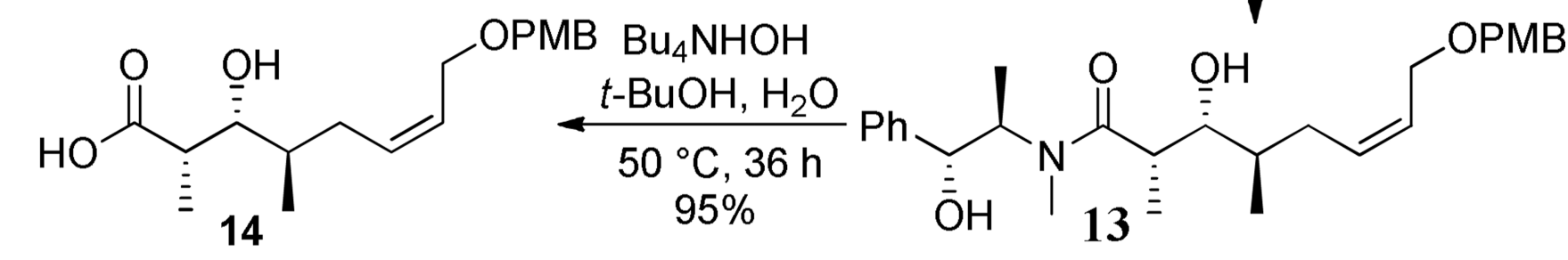<smiles>CNOC(=O)C(C)C(=O)OC</smiles>
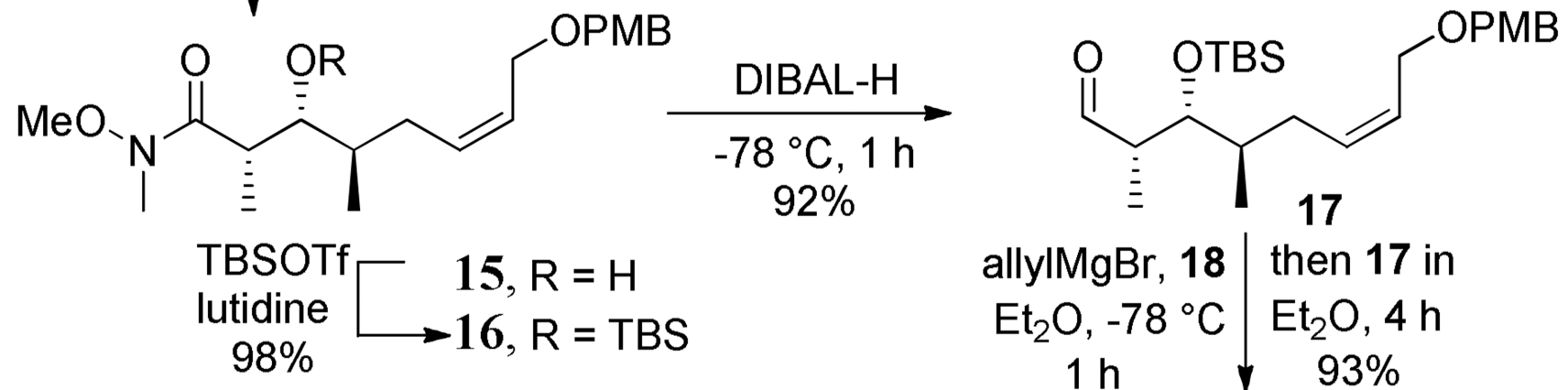

$$
\begin{array}{c|c}
\text { allylMgBr, 18 } & \text { then 17 in } \\
\mathrm{Et}_{2} \mathrm{O},-78{ }^{\circ} \mathrm{C} & \mathrm{Et}_{2} \mathrm{O}, 4 \mathrm{~h} \\
1 \mathrm{~h} & 93 \%
\end{array}
$$
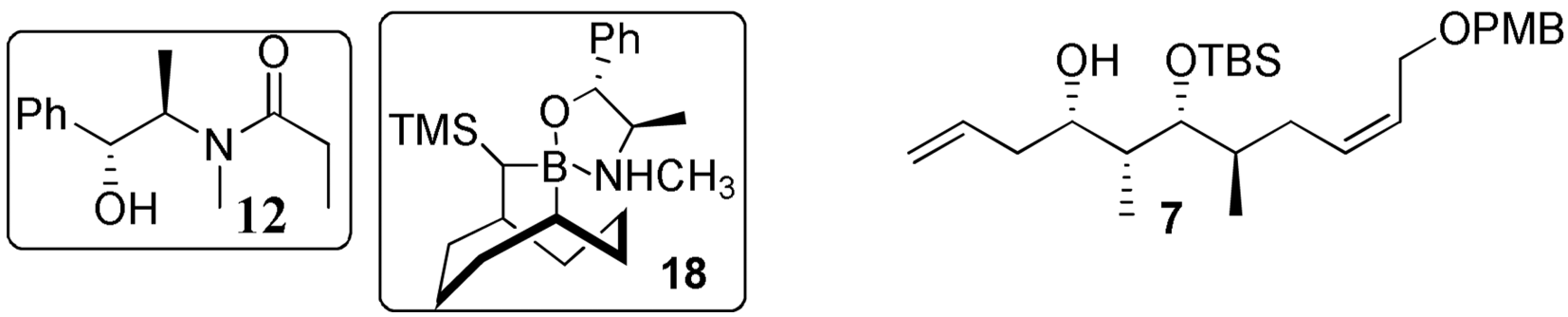

Scheme 1.

Synthesis of allylic aclohol 7. 


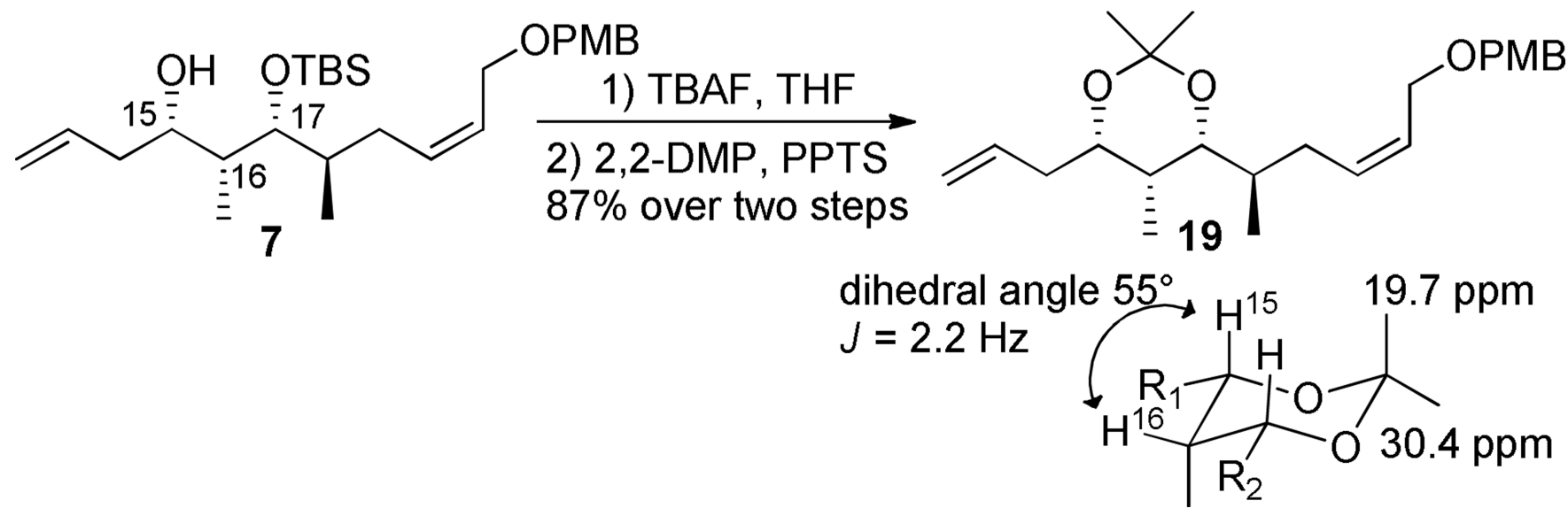

Scheme 2.

Stereochemistry confirmation at C-16 carbon. 
1) $\mathrm{Bu}_{4} \mathrm{NHOH}$,

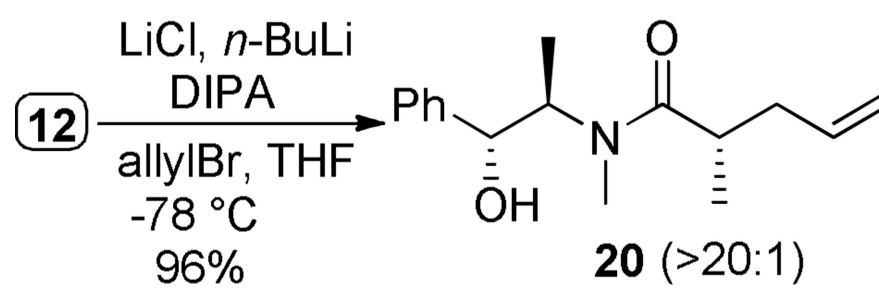

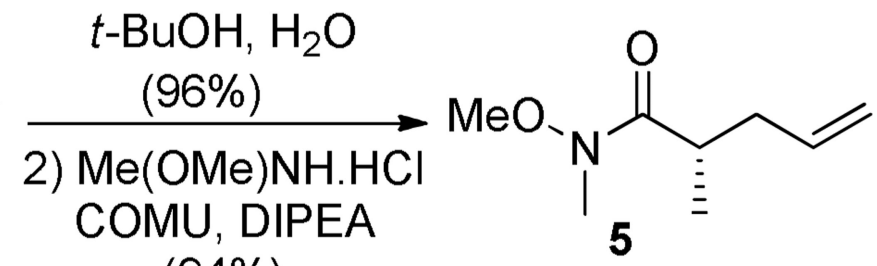
$(94 \%)$

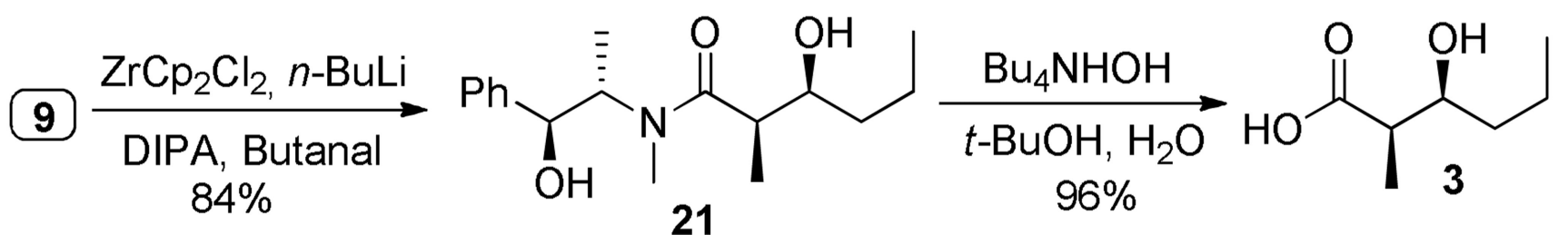

Scheme 3.

Synthesis of the Weinreb amide $\mathbf{5}$ and side chain acid $\mathbf{3}$. 
<smiles>C=CC[C@H](C)C(=O)Cc1cc(OC)cc(OC)c1C(=O)O[C@H](CC=C)[C@@H](C)[C@H]([O-])[C@@H](C)C/C=C\CO[R15](C)(C)C</smiles>

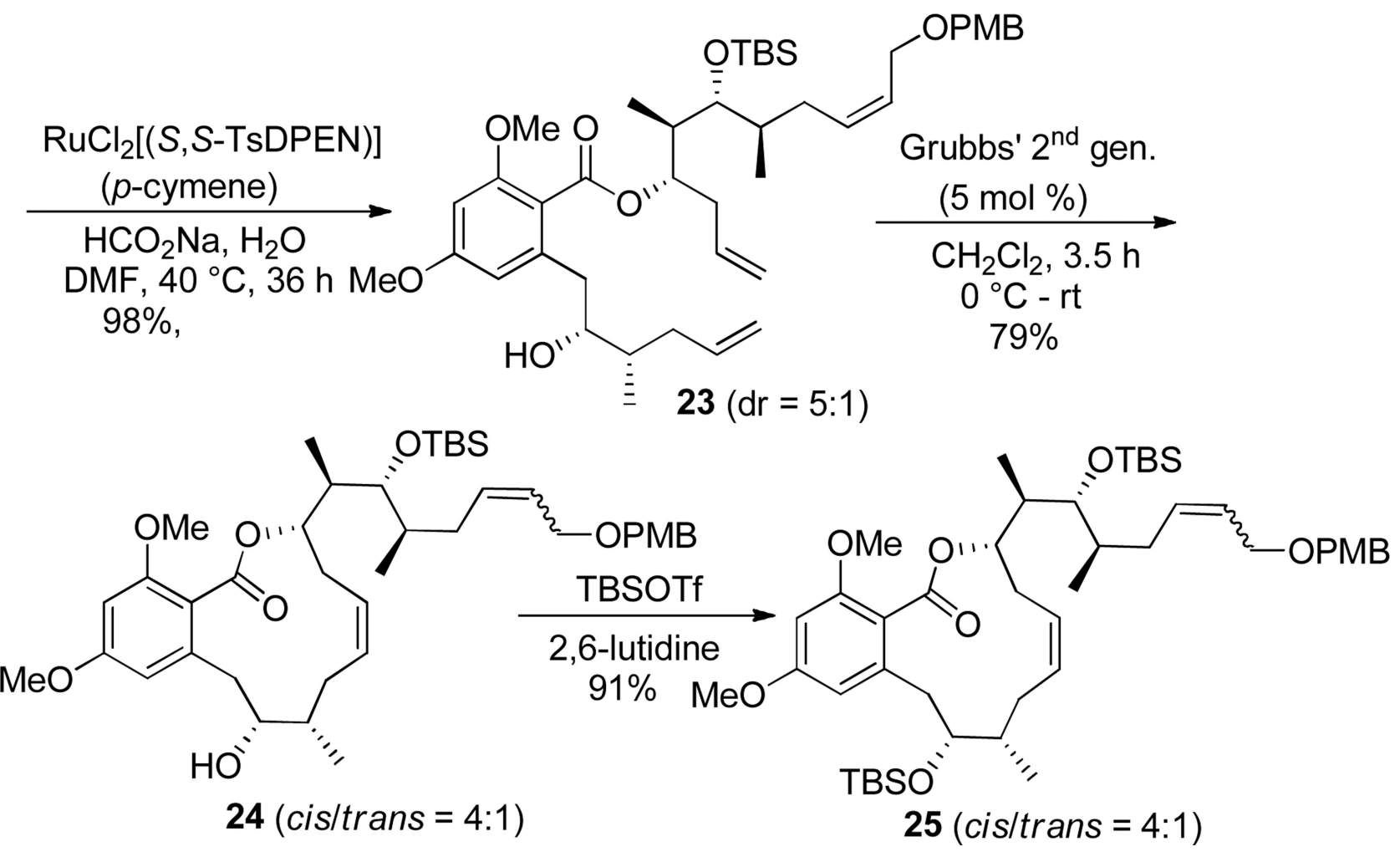

Scheme 4.

Synthesis of key macrolactone 25. 

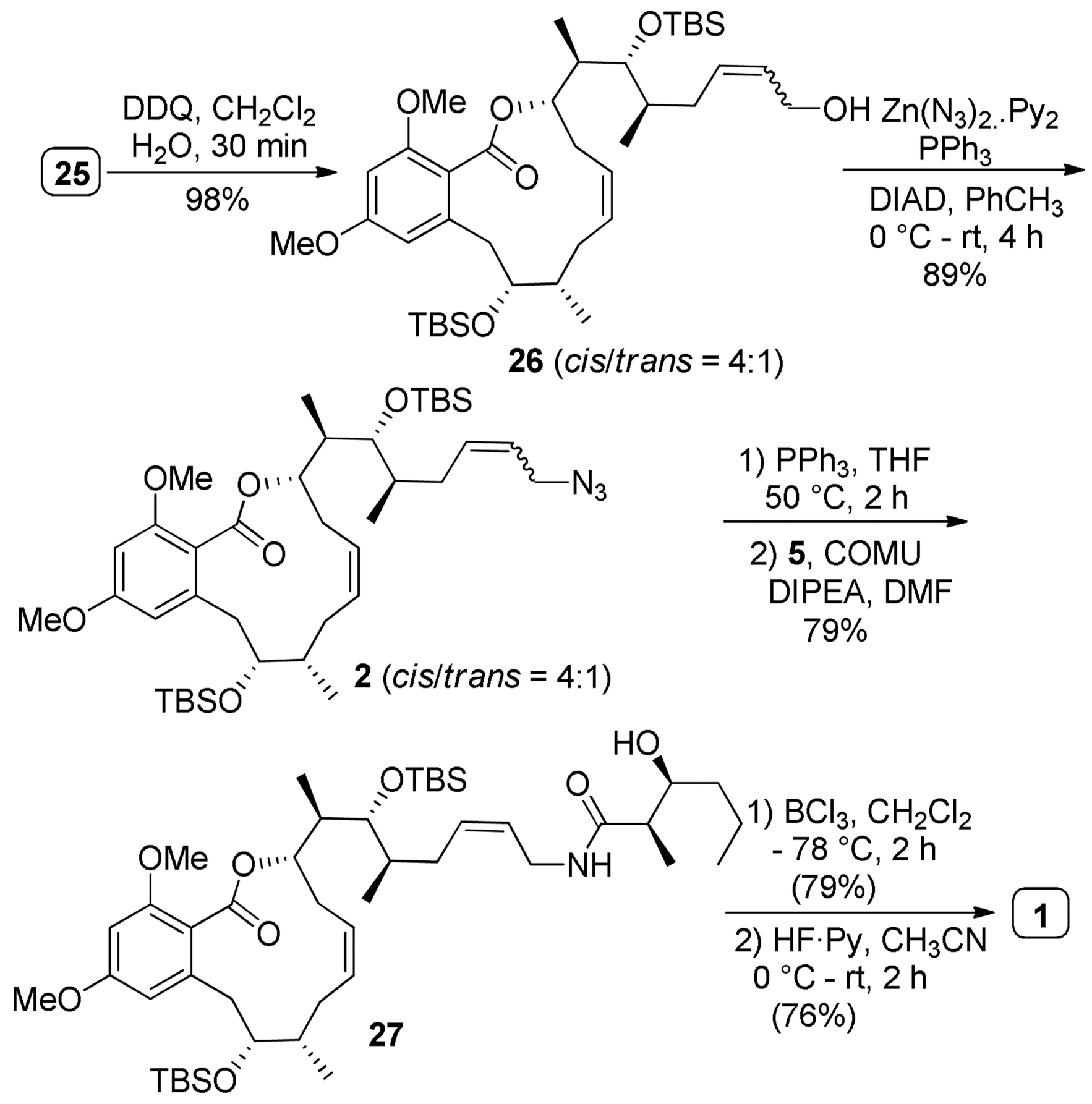

Scheme 5.

Conversion of $\mathbf{2 5}$ to cruentaren A (1). 